Yoko Tsushima $\cdot$ S. Emori · T. Ogura

M. Kimoto • M. J. Webb - K. D. Williams

M. A. Ringer - B. J. Soden - B. Li • N. Andronova

\title{
Importance of the mixed-phase cloud distribution in the control climate for assessing the response of clouds to carbon dioxide increase: a multi-model study
}

Received: 7 June 2005/ Accepted: 6 December 2005

(C) Springer-Verlag 2006

\begin{abstract}
We have conducted a multi-model intercomparison of cloud-water in five state-of-the-art AGCMs run for control and doubled carbon dioxide climates. The most notable feature of the differences between the control and doubled carbon dioxide climates is in the distribution of cloud-water in the mixed-phase temperature band. The difference is greatest at mid and high latitudes. We found that the amount of cloud ice in the mixed phase layer in the control climate largely determines how much the cloud-water distribution changes for the doubled carbon dioxide climate. Therefore evaluation of the cloud ice distribution by comparison
\end{abstract}

Y. Tsushima $(\bowtie) \cdot$ S. Emori

Frontier Research Center for Global Change (FRCGC),

Japan Agency for Marine-Earth Science and Technology

(JAMSTEC), 3173-25 Showamachi, Kanazawa-ku,

236-0001 Yokohama City, Kanagawa, Japan

E-mail: tsussi@jamstec.go.jp

Tel.: + 81-45-7785580

Fax: + 81-45-7785707

T. Ogura $\cdot$ S. Emori

National Institute for Environmental Studies (NIES),

Tsukuba, Japan

M. Kimoto

Center for Climate System Research (CCSR),

University of Tokyo, Chiba, Japan

M. J. Webb · K. D. Williams · M. A. Ringer

Hadley Centre for Climate Prediction and Research, Met Office, Exeter, UK

B. J. Soden

Rosenstiel School for Marine and Atmospheric Science, University of Miami, Miami, FL, USA

B. $\mathrm{Li}$

Department of Atmospheric Sciences, University of Illinois at Urbana-Champaign (UIUC), Urbana, IL, USA

N. Andronova

Department of Atmospheric, Oceanic and Space Sciences, University of Michigan, Ann Arbor, MI, USA with data is important for future climate sensitivity studies. Cloud ice and cloud liquid both decrease in the layer below the melting layer, but only cloud liquid increases in the mixed-phase layer. Although the decrease in cloud-water below the melting layer occurs at all latitudes, the increase in cloud liquid in the mixed-phase layer is restricted to those latitudes where there is a large amount of cloud ice in the mixed-phase layer. If the cloud ice in the mixed-phase layer is concentrated at high latitudes, doubling of carbon dioxide might shift the center of cloud water distribution poleward which could decrease solar reflection because solar insolation is less at higher latitude. The magnitude of this poleward shift of cloud water appears to be larger for the higher climate sensitivity models, and it is consistent with the associated changes in cloud albedo forcing. For the control climate there is a clear relationship between the differences in cloud-water and relative humidity between the different models, for both magnitude and distribution. On the other hand the ratio of cloud ice to cloudwater follows the threshold temperature which is determined in each model. Improved measurements of relative humidity could be used to constrain the modeled representation of cloud water. At the same time, comparative analysis in global cloud resolving model simulations is necessary for further understanding of the relationships suggested in this paper.

\section{Introduction}

Considerable uncertainty remains in the estimates obtained from GCM simulations of climate sensitivity (the equilibrium global temperature change caused by a doubling of atmospheric carbon dioxide). The largest uncertainty is in cloud feedback (Cess et al. 1990). One focus of the Cloud Feedback Model Intercomparison 
Project (CFMIP, McAvaney and Le Treut (2003); http://www.cfmip.net) has been to provide a systematic comparison of cloud feedbacks in different climate models. Webb et al. (2006) analyzed model output from CFMIP and showed that, for an ensemble of 9 CFMIP slab ocean experiments, the values of climate sensitivity obtained range from 2.3 to $6.3^{\circ} \mathrm{C}$.

Many studies have attempted to reduce the uncertainty of cloud feedback in models. Cloud-water is a physical parameter which is strongly related to the reflection of solar radiation by clouds. Statistical cloud schemes such as Le Treut and $\mathrm{Li}$ (1991) and prognostic cloud schemes such as Rotstayn (1997) (which conserves water) have come to be more often implemented in models than diagnostic schemes. Senior and Mitchell (1993) showed that the partitioning of the liquid and ice phases of water (Fowler et al. 1996; Lohmann and Roeckner 1996) affects the sensitivity of a model. Many flight studies have been conducted in order to estimate the temperature dependency for the partitioning of liquid and ice in clouds (e.g. Feigelson 1978; Bower et al. 1996; Cober et al. 2001), but widely different results have been obtained and no consensus has been reached to date. Recently, modeling of microphysical processes, which include the detailed treatment of each phase of cloud, shape, and droplet size distribution has become feasible (e.g. Rotstayn et al. 2000). Cloud-water is a basic variable which is used in the formulation of cloud microphysics but there is no suitable global observation data for the climatology of the vertical profile of whole clouds available for model validation.

Part of the CFMIP output is a collection of modeled cloud-water profiles for control (atmospheric carbon dioxide concentration $=285.431 \mathrm{ppmv}$ ) and doubled carbon dioxide (hereafter $2 \times \mathrm{CO}_{2}$ ) climates. This is the first model intercomparison to compare the cloud-water not only in the control climate but also for the $2 \times \mathrm{CO}_{2}$ climate. In this study we analyze the distribution of cloud water in order to explore how the differences between the modeled control climates relate to the changes found for the $2 \times \mathrm{CO}_{2}$ climates. In particular we analyze the distribution and partitioning of the ice and liquid phases of the cloud, to see how the partitioning in each model affects both the distribution of cloud in the control climate and the change in the distribution for the $2 \times \mathrm{CO}_{2}$ climate.

\section{Data and model description}

\subsection{General description of the models}

The model outputs used in this study are from CFMIP. The CFMIP ensemble consists of 9 atmospheric GCMs coupled to a mixed layer ocean model run for control and $2 \times \mathrm{CO}_{2}$ climates. In this paper we use output from 5 models, which happen to include the lowest climate sensitivity model $\left(2.3^{\circ} \mathrm{C}\right)$ and highest climate sensitivity model $\left(6.3^{\circ} \mathrm{C}\right)$ from the full 9 model CFMIP ensemble.
The number of the models used for the analysis is smaller than Webb et al. (2006) because the output for all models was not available at the time this analysis was made.

The models which are analyzed in this study are as follows. The University of Illinois at Urbana-Champaign (UIUC) model is described in Yang et al. (2000) and Andronova et al (1999), and its atmospheric resolution is N36/L24. The Geophysical Fluid Dynamics Laboratory (GFDL) AM2 model is described by GFDL GAMDT (2004) and has atmospheric resolution of N72/ L24. The Hadley Centre climate model (HadSM4) described in Webb et al. (2001) is a development version of HadSM3 (Pope et al. 2000). It has an atmospheric resolution of N48/L38. Two model versions of the CCSR/ NIES/FRCGC group model (K-1 model developers 2004; Center for Climate System Research/National Institute of Environmental Studies/Frontier Research Center for Global Change, Japan Agency for MarineEarth Science and Technology) are included in our study. Both have an atmospheric resolution of T42/L20, but differ in the parameterization of cloud. The models have different climate sensitivity, and here, we refer to the lower and higher sensitivity versions as "MIROC low" and "MIROC high", respectively. The climate sensitivities of the 5 models are $2.3^{\circ} \mathrm{C}$ for UIUC, $2.9^{\circ} \mathrm{C}$ for GFDL, $3.6^{\circ} \mathrm{C}$ for $\mathrm{HadSM} 4,4.0^{\circ} \mathrm{C}$ for "MIROC low", and $6.3^{\circ} \mathrm{C}$ for "MIROC high".

In this study we analyze climatological variables, made from 20 year averages of model output. We interpolated all the model output to the same grid volume in order to make fair comparisons. It has $2.5^{\circ} \times 2.5^{\circ}$ horizontal grid, WMO standard pressure levels compatible with reanalysis products: $1,000,925,850,700$, $600,500,400,300,250,200,150,100,70,50,30,20$, and $10 \mathrm{hPa}$.

\subsection{Cloud parameterization of the models}

The treatment of cloud water in each of the models is summarized in Table 1. For the equations for cloud ice, UIUC and, "MIROC high" separate cloud liquid and cloud ice by temperature. "MIROC low" also separates cloud liquid and cloud ice by temperature, but the liquid from melted cloud ice is converted to rain. Prognostic equations for cloud ice including physically based transfer terms are included in the GFDL and HadSM4 models. The scheme in the GFDL model is based on Rotstayn (1997) and Rotstayn et al. (2000). The scheme in HadSM4 is described in Wilson and Ballard (1999). The central part of these prognostic schemes is the Bergeron-Findeisen process in which the ice crystals grow more efficiently from the vapor stage; this follows from the difference between the values of saturation vapor pressure over an ice surface, when compared with a water surface. In these mixed phase clouds the air is close to being saturated with respect to liquid water, but is super- 
Table 1 Summary of cloud schemes in 5 models

\begin{tabular}{|c|c|c|c|c|}
\hline & Prognostic variable (sub-grid distribution) & $\begin{array}{l}\text { Distinction of cloud liquid, } \\
\text { cloud ice }\end{array}$ & $\mathrm{Tc}, \mathrm{I}\left({ }^{\circ} \mathrm{C}\right)^{\mathrm{a}}$ & $\mathrm{Tc}, 1\left({ }^{\circ} \mathrm{C}\right)^{\mathrm{b}}$ \\
\hline MIROC high & $\begin{array}{l}\text { Vapor + cloud (uniform PDF), } \\
\text { Le Treut and Li (1991) }\end{array}$ & Separation by temperature & -25 & -5 \\
\hline MIROC low & $\begin{array}{l}\text { Vapor + cloud [exclude melted cloud ice] } \\
\text { (uniform PDF), Le Treut and Li (1991) }\end{array}$ & $\begin{array}{l}\text { Separation by temperature } \\
\text { (exclude melted ice) }\end{array}$ & -15 & 0 \\
\hline HadSM4 & $\begin{array}{l}\text { Vapor }+ \text { cloud liquid (triangular PDF), } \\
\text { Smith (1990); cloud ice (triangular PDF), } \\
\text { Wilson and Ballard } 1999\end{array}$ & Prognostic equation for cloud ice & $-40^{\mathrm{c}}$ & 0 \\
\hline UIUC & Cloud (no variance), Sundqvist $(1978,1988)$ & Separation by temperature & -30 & 0 \\
\hline
\end{tabular}

${ }^{\text {a }}$ Threshold temperature for all water converting to ice

${ }^{\mathrm{b}}$ Threshold temperature for all water defined to be liquid

${ }^{\mathrm{c}}$ Temperature of homogeneous nucleation

saturated (an unstable phase) with respect to ice. Consequently, in mixed phase clouds, ice crystals grow from the vapor phase much more rapidly than do the nearby droplets. The transfer terms which are in both models are: homogeneous nucleation of ice crystals, heterogeneous nucleation of ice crystals (BergeronFindeisen process), vapor deposition and sublimation of ice, melting of cloud ice, accretion, fall/precipitation of ice. The GFDL scheme has 'cloud ice' and 'precipitating ice (snow)'; melted cloud ice becomes cloud liquid water, and melted snow becomes rain; snow captures the cloud liquid water (accretion). In the HadSM4 scheme, 'ice' is used to describe all frozen water in large-scale clouds, and there is not a path from cloud ice to cloud liquid; melted cloud ice becomes rain; riming of liquid by ice is included; 'ice' captures raindrops.

All of the models have a threshold temperature for all water to convert to ice, and one for all water to be liquid. This is the case whether the models solve separate equations for liquid and ice, or whether they separate liquid and ice water diagnostically. However, the temperature range for which the existence of mixed phase (liquid + ice) is permitted is different for different models. The method of cloud overlap and the definition of cloud optical properties, which affect the radiative effect of cloud water, are summarized in Table 2. These also differ between models.

For comparison with observations, we use the Earth Radiation Budget Experiment (ERBE) S-9 data (Harrison et al. 1990) and reanalysis data from the European Center for Medium range Weather Forecast (ECMWF) (ERA40, Kållberg et al. 2004).

\section{Cloud distributions in the control climate}

Figure 1 shows the zonal averaged cloud water for the control climate for all 5 models, which includes total available cloud water (liquid, ice, and convective cloud).

The UIUC and GFDL sub-plots do not include convective cloud water, and the HadSM4 and the two MIROC sub-plots do include convective cloud water. The sub-plots are positioned in order of climate sensitivity, highest to lowest, top to bottom (i.e., "MIROC high", "MIROC low", HadSM4, GFDL, and UIUC). There are clear differences visible between the model outputs for both the amount and the (horizontal and

Table 2 Summary of treatment of cloud radiative effects in 5 models

\begin{tabular}{|c|c|c|c|}
\hline & Cloud overlap & $\begin{array}{l}\text { SW radiative property } \\
\text { for cloud ice }\end{array}$ & SW radiative property for cloud liquid \\
\hline MIROC high & Max/random & Effective radius $=40 \mu \mathrm{m}$ & $\begin{array}{l}\text { Mode radius from the number of cloud droplet } \\
\text { (function of aerosol mass: sulfate, organic carbon, sea salt), } \\
\text { Boucher and Lohmann (1995) }\end{array}$ \\
\hline MIROC low & Max/random & Effective radius $=40 \mu \mathrm{m}$ & $\begin{array}{l}\text { Mode radius from the number of cloud droplet } \\
\text { (function of aerosol mass: sulfate, organic carbon, sea salt), } \\
\text { Boucher and Lohmann (1995) }\end{array}$ \\
\hline GFDL & Random & $\begin{array}{l}\text { Function of temperature } \\
\text { (Donner et al. 1997) }\end{array}$ & $\begin{array}{l}\text { Effective radius }(<10.6 \mu \mathrm{m}) \text { diagnosed from an assumed } \\
\text { cloud droplet number concentration: } 300 \mathrm{~cm}^{-3} \text { (land), } \\
100 \mathrm{~cm}^{-3} \text { (ocean) }\end{array}$ \\
\hline UIUC & $\begin{array}{l}\text { Max/random } \\
\text { among the three } \\
\text { vertical categories }\end{array}$ & Effective radius $=70 \mu \mathrm{m}$ & $\begin{array}{l}\text { Equivalent radius from the number of cloud droplet } \\
\text { (function of the sulfate aerosol mass), } \\
\text { Boucher and Lohmann (1995) }\end{array}$ \\
\hline
\end{tabular}



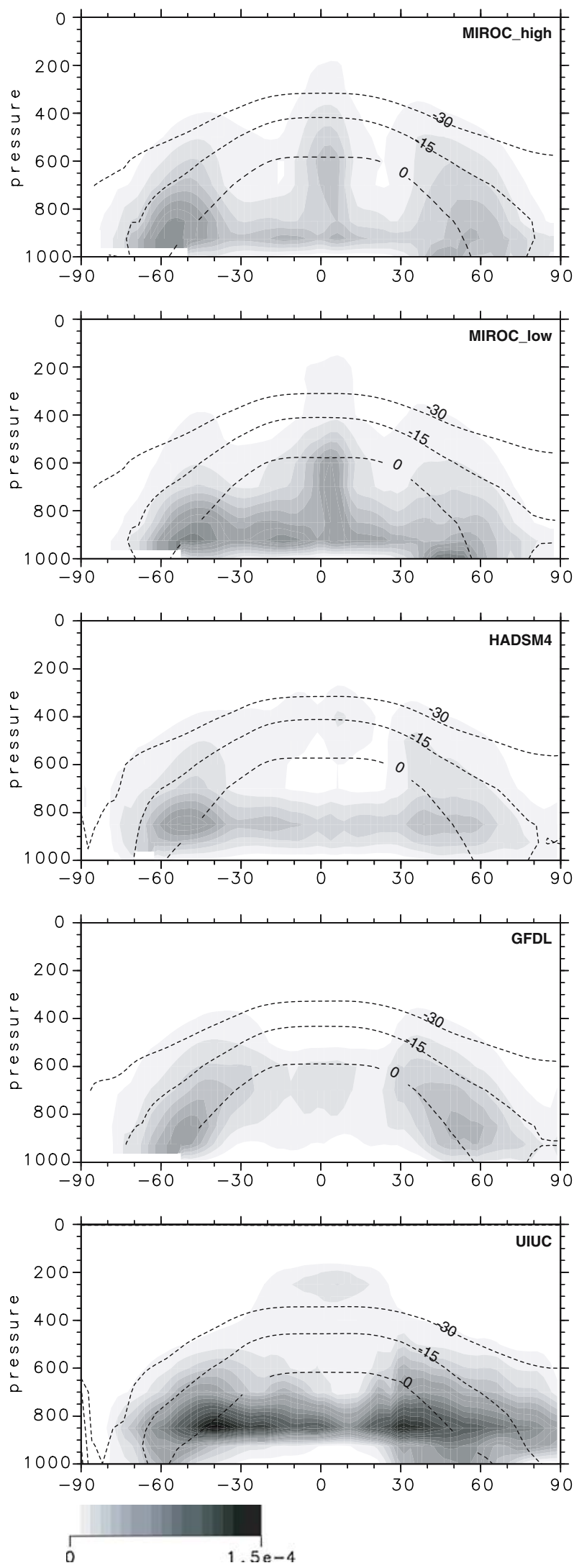

Fig. 1 Zonally averaged annual mean cloud water $[\mathrm{kg} / \mathrm{kg}]$ in 5 models in control climate. Dashed lines indicate the isothermal line of $0,-15$ and $-30^{\circ} \mathrm{C}$. From the top, "MIROC high", "MIROC low", HadSM4, GFDL and UIUC vertical) distribution of cloud water. At low latitudes, the position of the maximum in the vertical distribution of cloud water is higher for lower sensitivity models. At midlatitudes, there is a latitudinal slope in cloud water distribution, but the slope is more gradual in lower sensitivity models.

Figures 2 and 3 show the zonally averaged cloud liquid and cloud ice from large-scale condensation. The subtraction of both cloud liquid (Fig. 2) and cloud ice (Fig. 3) from the total cloud-water (Fig. 1) indicates the zonally averaged annual mean convective cloud-water in HadSM4, "MIROC low", and "MIROC high". The amounts of convective cloud-water and large scale condensation cloud-water are about the same in HadSM4, while in "MIROC low" and "MIROC high" there is much less convective cloud-water than largescale condensation cloud-water. When we separate the distribution of total cloud-water into cloud liquid and cloud ice and compare them between models we can see clear differences caused by the different cloud parameterizations in the 5 models.

In Fig. 2, the temperature of the top of the cloud liquid profile in UIUC, "MIROC low", and "MIROC high" corresponds to the threshold temperature for all water converting to ice in the model. On the other hand, the temperature of the top of cloud liquid profile in GFDL and HadSM4 is around $-15^{\circ} \mathrm{C}$, which is warmer than the threshold temperature for those models $\left(-40^{\circ} \mathrm{C}\right)$. In these two models, cloud ice is a prognostic variable, and the temperature is a threshold temperature of homogeneous nucleation of ice.

When the temperature is just below freezing ice can grow only slowly. This is because, at this temperature, the saturation vapor pressure with respect to ice is very close to the saturation vapor pressure with respect to liquid. However, when the temperature falls to below $-10^{\circ} \mathrm{C}$, ice nuclei can be activated. The cloud ice crystals then grow quickly, by vapor deposition at the expense of coexisting cloud liquid (Bergeron-Findeisen mechanism), and fall out of the cloud. This activation of ice makes the temperature of the top of cloud liquid profile around $-15^{\circ} \mathrm{C}$.

Cloud liquid distributions below the threshold temperature for all water converting to ice are quite different between models. The large-scale cloud water is relatively small in the HadSM4 model. It is related to the larger contribution of convective cloud in this model. The relevance of the distribution to the parameterizations is not clear.

Figure 3 shows the cloud ice content distribution for the 5 models. Cloud ice exists above and around the $0{ }^{\circ} \mathrm{C}$ temperature band (indicated by a dashed line). In "MIROC high", the altitude of the bottom boundary of the cloud ice profile is higher. This altitude corresponds to the critical temperature for all water defined to be liquid. In all of the models other than "MIROC high" it is $0^{\circ} \mathrm{C}$, while it is $-5^{\circ} \mathrm{C}$ in "MIROC high". However, the whole profile of cloud ice does not necessarily follow the temperature band. Relevance of the distribution to the parameterizations is not clear. 
Tsushima et al.: Importance of the mixed-phase cloud distribution
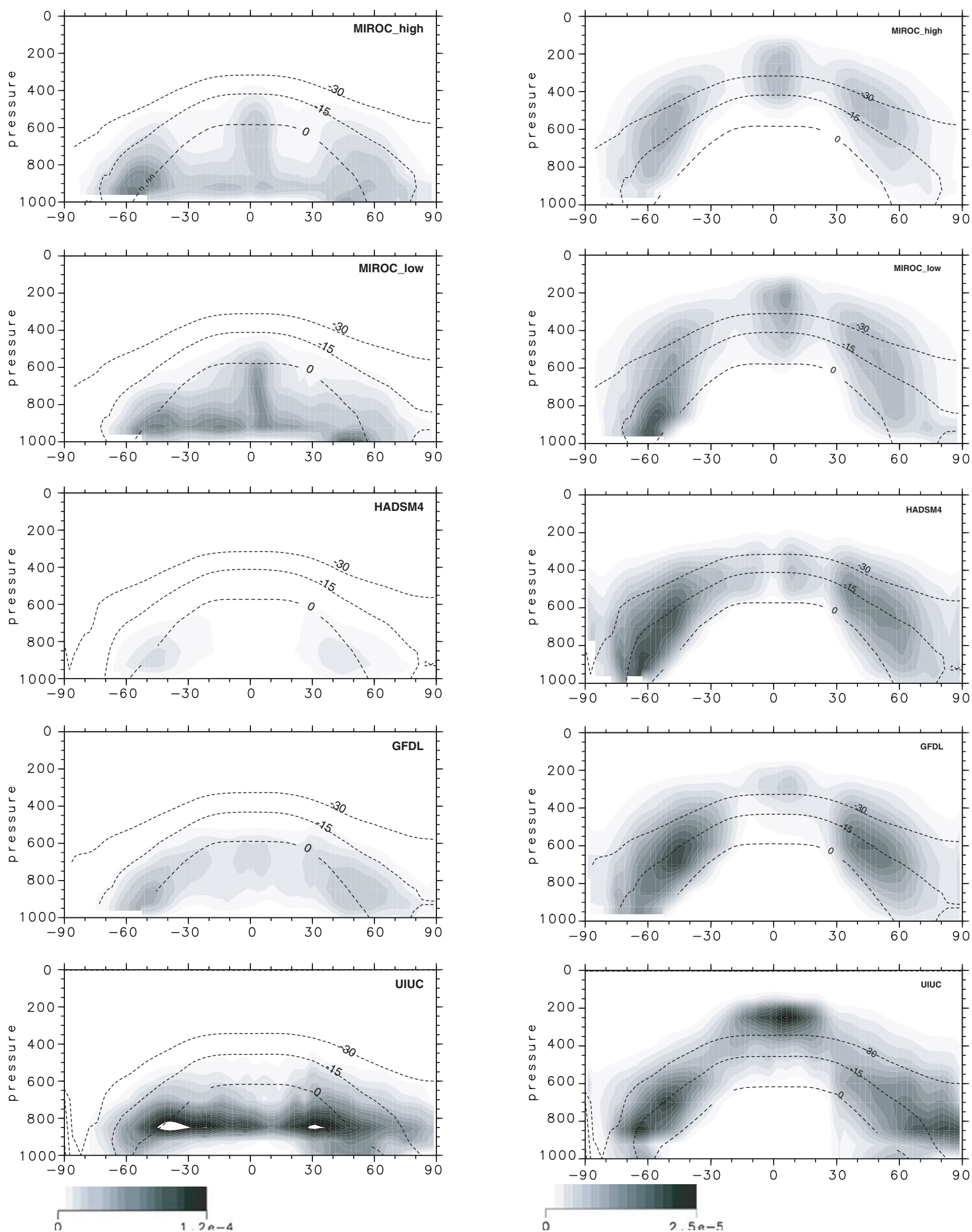

Fig. 2 Zonally averaged annual mean cloud liquid $[\mathrm{kg} / \mathrm{kg}]$ in 5 models in control climate. Dashed lines indicate the isothermal line of $0,-15$ and $-30^{\circ} \mathrm{C}$. From the top, "MIROC high", "MIROC low", HadSM4, GFDL and UIUC

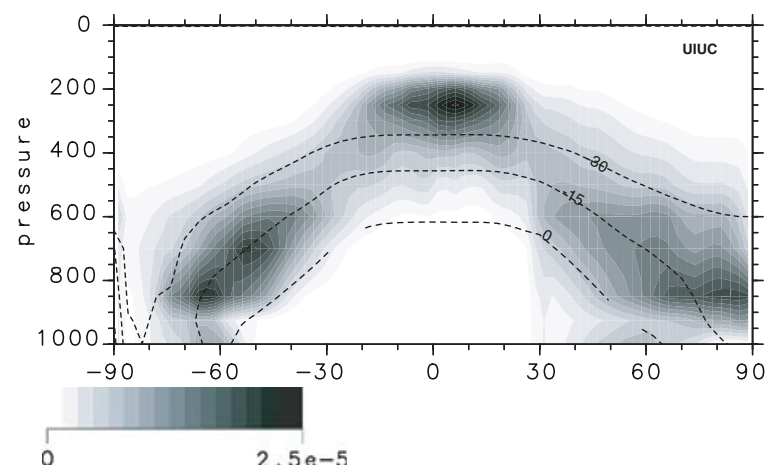

Fig. 3 Zonally averaged annual mean cloud ice $[\mathrm{kg} / \mathrm{kg}]$ in 5 models in control climate. Dashed lines indicate the isothermal line of 0 , -15 and $-30^{\circ} \mathrm{C}$. From the top, "MIROC high", "MIROC low", HadSM4, GFDL and UIUC 
To see the radiative effect of cloud in the 5 models, we calculate cloud albedo forcing. Cloud albedo forcing is an indicator of cloud's reflectivity of solar insolation, using the solar cloud forcing concept. Following Charlock and Ramanathan (1985), solar cloud forcing is defined as

$$
\mathrm{CF}_{\mathrm{S}}=\mathrm{R}_{\mathrm{S}}-\mathrm{R}_{\mathrm{S} 0} \text {, }
$$

where $R_{\mathrm{S}}$ and $R_{\mathrm{S} 0}$ are the net downward fluxes of solar radiations at the top of total sky and cloud-free (clear) sky. Cloud albedo forcing $\left(a_{\mathrm{f}}\right)$ is obtained by dividing solar cloud forcing by the solar insolation $\left(S_{0}\right)$,

$a_{\mathrm{f}}=\mathrm{CF}_{\mathrm{S}} / \mathrm{S}_{0}$.

Figure 4 shows the zonal mean cloud albedo forcing for the control climate in the 5 models, along with the observations from ERBE S-9 data (Harrison et al. 1990). Thin lines with no mark are the model values and the line with the circle marks is the observational data. The range in latitude is restricted to $60 \mathrm{~S}-60 \mathrm{~N}$ because of the difficulty in reliably determining solar cloud forcing over

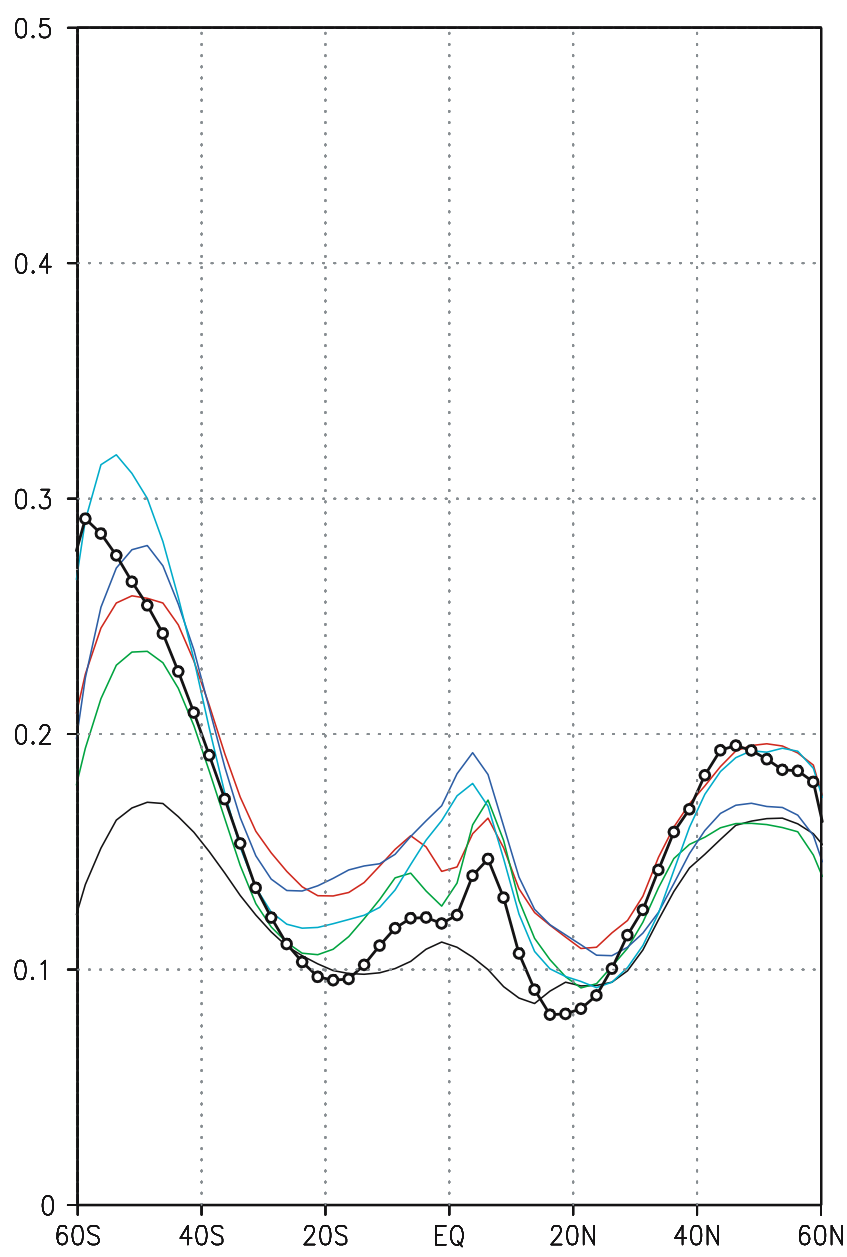

Fig. 4 Zonally averaged annual mean cloud albedo forcing. Thin lines are for models (black: UIUC, red: GFDL, green: HadSM4, blue: "MIROC low", light blue: "MIROC high"). Line with circle mark is observation polar regions covered by snow, sea ice and/or continental ice sheets with high surface albedo (Nemesure et al. 1994). Although all the models reproduce the observed characteristics of zonally averaged cloud albedo forcing, the magnitude of the zonally averaged albedo forcing varies by about $20 \%$ between models. The difference between the models is largest for mid-latitude cloud over the southern hemisphere. Comparing the cloud water distribution in Fig. 1 with the distribution of cloud albedo forcing in Fig. 4, we see that the model with more cloud water does not necessarily have greater cloud albedo forcing. The UIUC model has the largest total cloud water, but also the lowest cloud albedo forcing. GFDL, HadSM4, "MIROC low", and "MIROC high" have similar amounts of total cloud water, but HadSM4 has the lower cloud albedo forcing. Large scale cloud water is relatively small in the HadSM4 model, because of the larger contribution of convective cloud. The convective cloud has a much smaller coverage and its contribution to the radiative flux is often considered to be smaller than that of the large scale clouds. The smaller large scale cloud-water amounts are consistent with the smaller cloud albedo forcing in HadSM4. In the UIUC model, the particle radius of ice clouds is larger than in the other models. If there are two clouds with the same total cloud-water amount but consisting of particles with different sizes, those with the larger radius will have smaller reflectivity while those with smaller radius will have larger reflectivity. The larger ice cloud radius in the UIUC model partly contributes that model having the lowest cloud albedo forcing. Quantitative translation of the contribution of each parameter (cloud liquid, cloud ice, convective cloud water, cloud overlapping, cloud droplet radius, cloud-droplet number concentration) to the difference in cloud albedo forcing between models would require further analysis.

\section{Cloud water distributions for $2 \times \mathrm{CO}_{2}$ climate}

Figure 5 shows the differences in the total cloud water between the control and $2 \times \mathrm{CO}_{2}$ experiments. Also marked are the $-30,-15$ and $0^{\circ} \mathrm{C}$ contours for both the control (dashed line) and $2 \times \mathrm{CO}_{2}$ (solid line) climates. The characteristic changes for the $2 \times \mathrm{CO}_{2}$ climate compared to the control are a drying of the low-middle level below the $0{ }^{\circ} \mathrm{C}$ line and an increase in cloud water between the -30 and $0^{\circ} \mathrm{C}$ line. This characteristic is common for all the models, including both prognostic and diagnostic cloud schemes. The drying of the mid latitude troposphere by deeper vertical motion has been discussed in detail elsewhere (e.g., Mitchell and Ingram 1992; Wetherald and Manabe 1998).

Figures 6 and 7 show the contributions of ice and liquid cloud respectively to the change in cloud water for the $2 \times \mathrm{CO}_{2}$ climate. For all of the models, cloud ice decreases in the layer near $0^{\circ} \mathrm{C}$, and cloud liquid increases mostly within the layer between -30 and $0^{\circ} \mathrm{C}$, which 

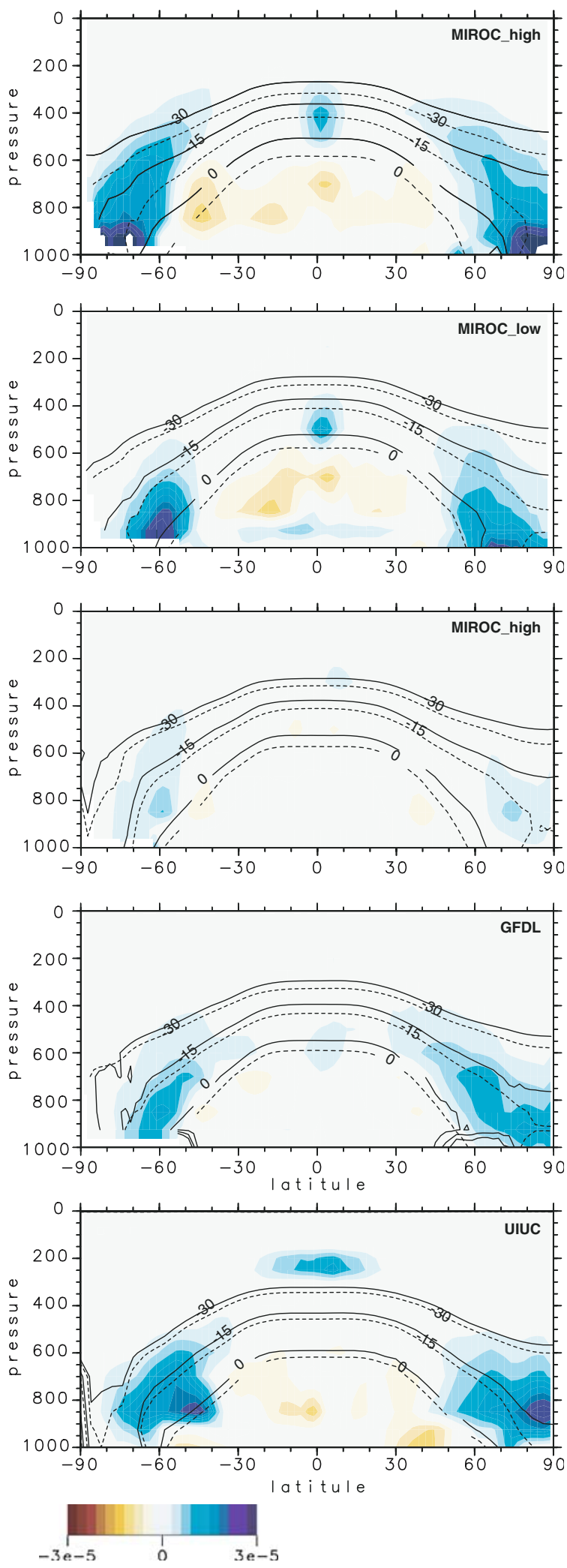

Fig. 5 Difference of annual mean cloud water amount between the control experiment and the $2 \times \mathrm{CO}_{2}$ experiment $[\mathrm{kg} / \mathrm{kg}]$ in 5 models (zonally averaged). Dashed lines indicate the isothermal line of 0 , -15 and $-30^{\circ} \mathrm{C}$ for control climate. Solid lines are for $2 \times \mathrm{CO}_{2}$ climate). From the top, "MIROC high", "MIROC low", HadSM4, GFDL and UIUC corresponds to the mixed phase layer where cloud liquid and cloud ice coexist.

As Senior and Mitchell (1993) wrote, the change in ice and liquid cloud are associated with the change in the phase of cloud. Generally ice cloud is more efficient to precipitate than liquid cloud (Bergeron-Findeisen effect). In the $2 \times \mathrm{CO}_{2}$ climate, some portion of water which was ice in the control climate has been re-distributed as liquid water. Since cloud liquid is less efficient to precipitate, the total amount of cloud water increases. The smaller droplet radius of cloud liquid compared to cloud ice contributes further to make the cloud more efficient at reflecting solar insolation.

Figure 6 shows the zonal averaged change in annual mean cloud ice content for the 5 models. Cloud ice decreases between the melting temperature bands of the control climate (indicated by a dashed line) and the $2 \times \mathrm{CO}_{2}$ climate (indicated by a solid line). The melting temperature is $-5^{\circ} \mathrm{C}$ in "MIROC high", and $0^{\circ} \mathrm{C}$ in the other 4 models. Cloud ice can exist in the mixed-phase layer which is above the melting layer, and increases in cloud ice are confined to altitudes above the layer where cloud ice decreases in the $2 \times \mathrm{CO}_{2}$ climate simulations.

Figure 7 shows that the cloud liquid increases across wider temperature bands than does the cloud ice. In this case, the increase is confined to the temperature band between the threshold temperature for all water converting to ice and the practical threshold temperature of the top of cloud liquid profile. The upper limit in GFDL model is around -20 , and $-15^{\circ} \mathrm{C}$ in $\mathrm{HadSM} 4$, and both are much higher than the homogenous nucleation temperature. According to the Bergeron-Findeisen effect, cloud ice deposition controls the upper bound for the increase of cloud liquid.

Although the amount of cloud liquid is larger than the amount of cloud ice in the control simulations, the differences in these quantities between the control and the $2 \times \mathrm{CO}_{2}$ experiments are similar. The change in the amount of convective cloud-water is quite small in all models, irrespective of whether its amount in the control climate is similar to the cloud-water amount (not shown). In HadSM4, the change in the amount of cloudwater is small for both convective and large-scale cloud. This is the reason for the smaller change in total cloud water distribution in this model.

\section{Change in mixed-phase layer cloud profile in mid-latitude in $2 \times \mathrm{CO}_{2}$ climate}

The magnitude of the increase in the cloud liquid in the mixed-phase layer when $\mathrm{CO}_{2}$ is doubled varies for different latitudes (see Fig. 7). In the tropics, cloud water is mainly present at lower levels with a temperature much higher than $0^{\circ} \mathrm{C}$ so that the contribution of the phase change does not have a great influence on the system as a whole. At mid and high latitudes, cloud water is mainly present in the temperature band of mixed phase clouds. At higher latitudes more of the vertical profile of the 
Tsushima et al.: Importance of the mixed-phase cloud distribution
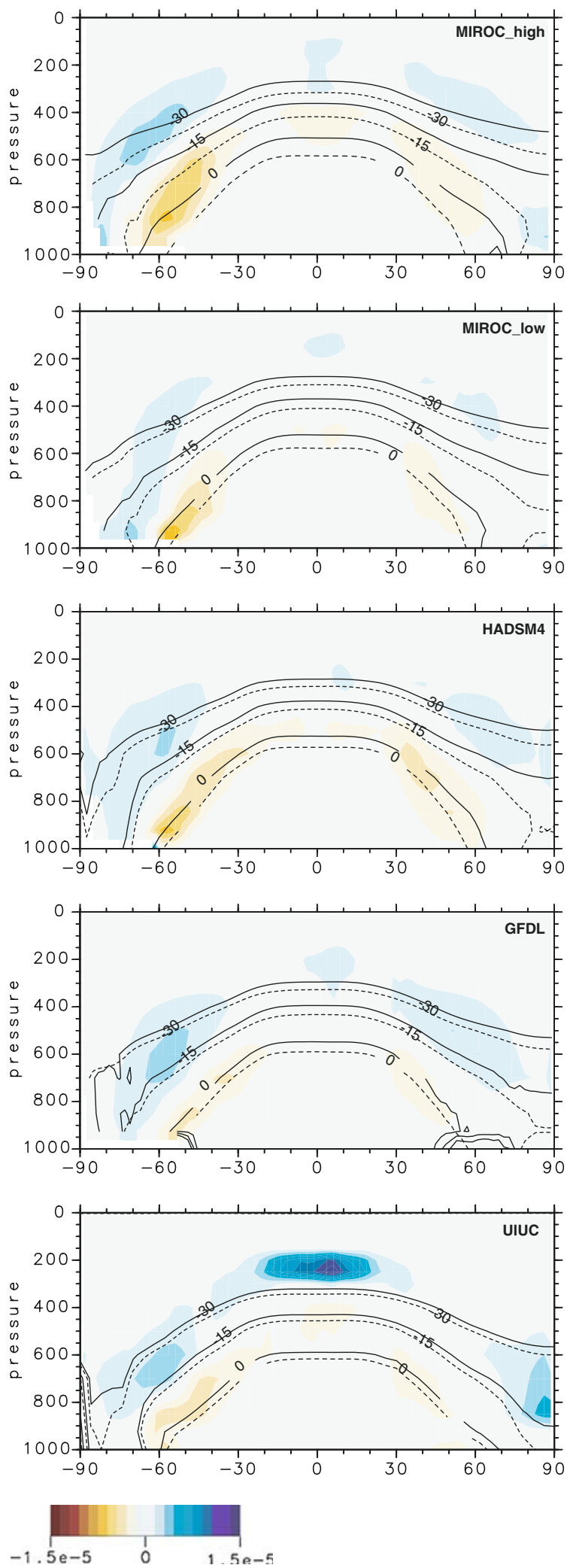

Fig. 6 Difference of annual mean cloud ice between the control experiment and the $2 \times \mathrm{CO}_{2}$ experiment $[\mathrm{kg} / \mathrm{kg}]$ in 5 models (zonally averaged). Dashed lines indicate the isothermal line of $0,-15$ and $-30^{\circ} \mathrm{C}$ for control climate. Solid lines are for $2 \times \mathrm{CO}_{2}$ climate). From the top, "MIROC high", "MIROC low", HadSM4, GFDL and UIUC
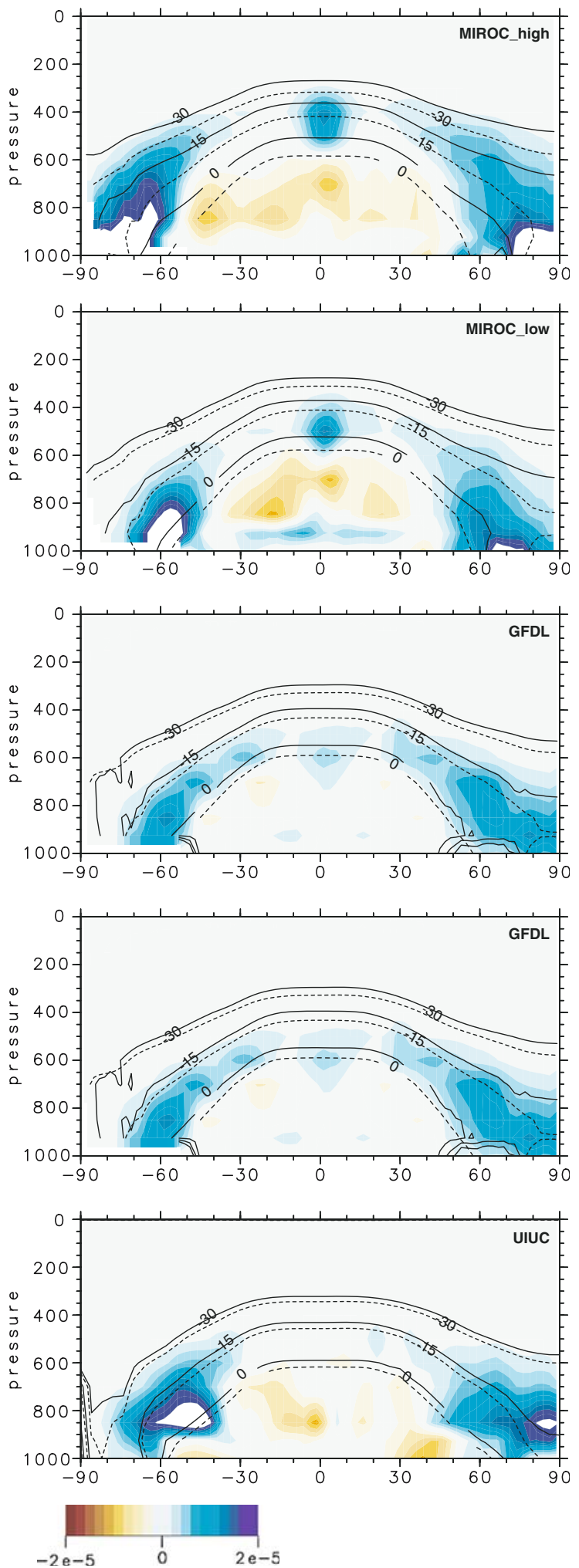

Fig. 7 Difference of annual mean cloud liquid between the control experiment and the $2 \times \mathrm{CO}_{2}$ experiment $[\mathrm{kg} / \mathrm{kg}]$ in 5 models (zonally averaged). Dashed lines indicate the isothermal line of $0,-15$, and $-30^{\circ} \mathrm{C}$ for control climate. Solid lines are for $2 \times \mathrm{CO}_{2}$ climate). From the top, "MIROC high", "MIROC low", HadSM4, GFDL, and UIUC 
atmosphere is covered in the mixed phase layer so the changes in liquid and ice cloud are greater. Furthermore, the magnitude of temperature increase is greater at higher latitude. These factors make the magnitude of the change in the phase of cloud greater at mid-high latitude. The higher latitudes are, however, usually covered by a bright surface, so the radiative effect of the change in cloud phase is less efficiently. The mid latitude southern ocean is the region where change in cloud phase actually has the greatest influence on radiative flux at the top of the atmosphere. We therefore choose the mid latitude area in the southern hemisphere for further analysis.

To see the difference between the models in the change of the cloud phase caused by doubling $\mathrm{CO}_{2}$, we analyzed the change in liquid and ice cloud in the mixed phase temperature band for each model. We interpolate the vertical profile of clouds and atmosphere into temperature bands, rather than pressure bands, in order to see more clearly the changes with temperature increase. The outputs from both the control and $2 \times \mathrm{CO}_{2}$ simulations are interpolated according to the temperature bands of the control climate. The annually averaged vertical profiles of cloud liquid and cloud ice are redivided into 8 layers as follows: temperature range above $0^{\circ} \mathrm{C}$; temperature range below $-30^{\circ} \mathrm{C} ; 6$ layers between 0 and $-30^{\circ} \mathrm{C}$ in $5^{\circ} \mathrm{C}$ intervals. We define the layers between 0 and $-30^{\circ} \mathrm{C}$ as the "mixed-phase layer". Although the polar region is an important area where mixed phase clouds dominate, we restrict the latitudinal region from $55 \mathrm{~S}$ to $30 \mathrm{~S}$ because of the difficulty in interpolating the atmospheric layer into temperature bands in the area where inversions of atmospheric temperature occur.

Figure 8 shows the profiles of the ice cloud in control climate (dashed line), the differences between the $2 \times \mathrm{CO}_{2}$ and control simulations in the ice cloud (solid line with square markers) and liquid cloud (solid line), averaged over the $55 \mathrm{~S}$ to $30 \mathrm{~S}$ latitudinal area. (The labels on the vertical axes indicate the temperature band in the $2 \times \mathrm{CO}_{2}$ climate). In all the models the changes in cloud ice and cloud liquid are opposite in sign for the lower levels of mixed phase, but the increase of cloud liquid is greater than the cloud ice decrease for the lower climate sensitivity models. In each model, the vertical profile of the increase in cloud liquid is similar to that of the cloud ice in control climate. In higher climate sensitivity models, the increase in cloud-water is small, despite the magnitude of the decrease of ice cloud ranges for the lower temperature bands. In "MIROC high", liquid cloud decreases at lower altitude.

The peak of the decrease in ice cloud is in the temperature range -5 to $0^{\circ} \mathrm{C}$ for 3 out of the 5 models. Because "MIROC high" sets the mixed phase below $-5^{\circ} \mathrm{C}$, the peak for this model is in the lower temperature range: -10 to $-5^{\circ} \mathrm{C}$ band. The temperature band where the decrease in ice cloud is smaller corresponds to the altitude where all cloud becomes cloud ice. It is $-25^{\circ} \mathrm{C}$ for "MIROC high", $-15^{\circ} \mathrm{C}$ for "MIROC low", around $-15^{\circ} \mathrm{C}$ for prognostic cloud scheme models: HadSM4 and GFDL. For UIUC, this altitude corresponds to $-20^{\circ} \mathrm{C}$.

\section{Change in latitudinal distribution of cloud water and albedo forcing caused by doubling $\mathrm{CO}_{2}$}

Figure 9 shows the zonal mean annually averaged cloud albedo forcing over $60 \mathrm{~S}$ to $30 \mathrm{~S}$ in the control and $2 \times \mathrm{CO}_{2}$ climates. In all of the models this increases poleward until it has a maximum value around $50 \mathrm{~S}$, and then it decreases slightly until $90 \mathrm{~S}$. Under the $2 \times \mathrm{CO}_{2}$ climate, the cloud albedo forcing decreases at lower latitudes, whereas it increases at higher latitudes. The magnitude of the decrease in cloud albedo forcing is larger in the model with the higher climate sensitivity. Compared to the control climate, cloud albedo forcing in the $2 \times \mathrm{CO}_{2}$ climate looks like it shifts poleward. The poleward shift of the cloud albedo forcing causes a reduction in the reflection of solar insolation, because the solar insolation is smaller at higher latitudes.

Yin (2005) found a poleward shift of storm tracks in a multi-model analysis of $2 \times \mathrm{CO}_{2}$ climates. We define the central latitude of vertically integrated cloud water (yicldw) in the latitude band between $90 \mathrm{~S}$ and $30 \mathrm{~S}$ as follows.

$y_{\text {icldw }}=\frac{\sum y \cdot \operatorname{icldw}(y)}{\sum \operatorname{icldw}(y)}$,

where $\operatorname{icldw}(y)$ is the zonally averaged vertically integrated annual mean cloud water at latitude $(y)$. Because vertically integrated cloud water data has not been submitted for HadSM4, we calculate it from the monthly mean cloud water profile data. The change in $y_{\text {icldw }}$ in $2 \times \mathrm{CO}_{2}$ is expressed as follows.

$$
\mathrm{d} y_{\text {icldw }}=y_{\text {icldw }}\left(2 \times \mathrm{CO}_{2}\right)-y_{\text {icldw }}\left(1 \times \mathrm{CO}_{2}\right)
$$

We show $y_{\text {icldw }}$ in the control climate and its change in $2 \times \mathrm{CO}_{2}$ climate in Table 3. The table shows that the center of the vertically integrated cloud water shifts more in the model with higher climate sensitivity.

We calculate the changes in solar cloud forcing with the polar shift of cloud water in 5 models. Cloud albedo forcing for the longitude $x$ and the latitude $y$ for the control climate of month $\mathrm{m}$ is written as $a_{\mathrm{f}}(x, y, m$, $\left.1 \times \mathrm{CO}_{2}\right)$. We shift the cloud albedo forcing from the control poleward by the same amount as the shift in the position of center latitude of vertically integrated cloud water for each model. The polar shifted cloud albedo forcing is expressed as follows.

$a_{\mathrm{f}}(x, y, m$, shift $)=a_{\mathrm{f}}\left(x, y+\mathrm{d} y_{\text {icldw }}, m, 1 \times \mathrm{CO}_{2}\right)$

We linearly interpolate the value of $a_{\mathrm{f}}\left(x, y+\mathrm{d} y_{\text {icldw }}\right.$, $\left.m, 1 \times \mathrm{CO}_{2}\right)$ from $2.5^{\circ} \times 2.5^{\circ}$ horizontal grid data of $a_{\mathrm{f}}(x$, $\left.y, m, 1 \times \mathrm{CO}_{2}\right)$. 
Fig. 8 The profiles of the ice cloud in control climate (dashed line), differences between the $2 \times \mathrm{CO}_{2}$ and control simulations in the ice cloud (solid line with square) and liquid cloud (solid line), averaged over $55 \mathrm{~S}$ to $30 \mathrm{~S}$ latitudinal area. (The labels on the vertical axes indicate the temperature band. 8 temperature bands for the vertical layer, averaged over the latitude area. (e.g. " -5 " is the band -5 to $0^{\circ} \mathrm{C}$, " 0 " indicates temperatures above $0^{\circ} \mathrm{C}$, and " -35 " is the value for temperature below $-30^{\circ} \mathrm{C}$ )
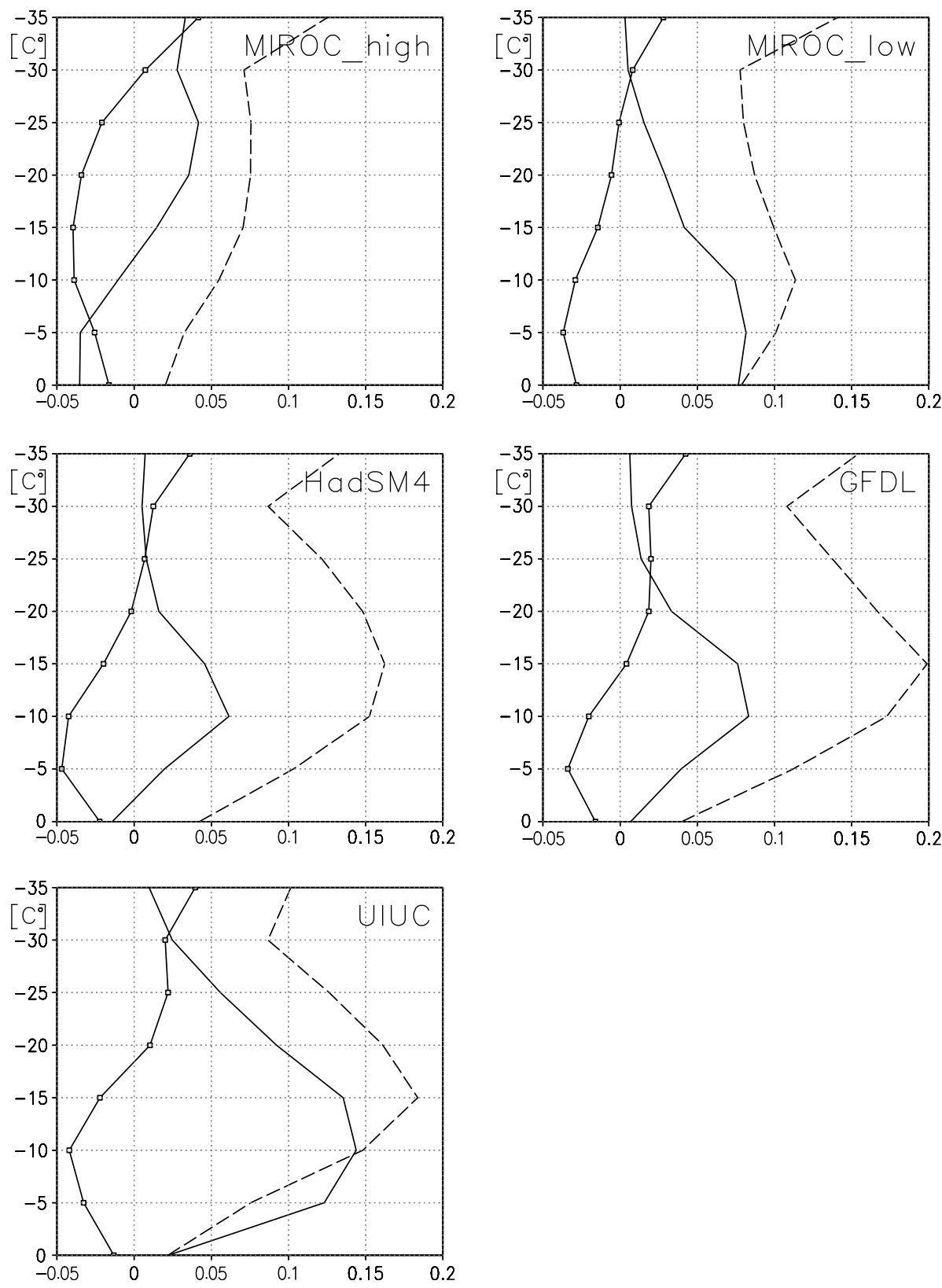

The polar shifted solar cloud forcing is

$\operatorname{CFs}(x, y, m, \operatorname{shift})=S_{0}(y, m) \times a_{\mathrm{f}}(x, y, m$, shift $)$.

We show the change in the annually averaged solar cloud forcings averaged over $60 \mathrm{~S}$ to $30 \mathrm{~S}$ for $2 \times \mathrm{CO}_{2}$ climate and for the polar shift of cloud albedo forcing from $1 \times \mathrm{CO}_{2}$ climate in Fig. 10. We find that the magnitude of the weakening in solar cloud forcing due to the polar shift of cloud water distribution is approximately the same as the actual decrease in solar cloud forcing for the $2 \times \mathrm{CO}_{2}$ climate.

The changes in cloud water caused by doubling $\mathrm{CO}_{2}$ occur at different latitudes for the cloud water in the layer below the melting layer and that in the mixedphase layer. Ice and liquid cloud decrease in the layer below the melting layer whereas the increase in cloud liquid occurs in the mixed-phase layer. An increase in cloud liquid in the mixed-phase layer occurs at higher latitudes where large amount of cloud ice exists in the mixed phase layer. This may causes a poleward shift of the position of cloud water maximum.

\section{Distribution of mixed-phase cloud water and relative humidity in mid-latitude in the control climate}

Not only the difference in the amount of precipitation in ice and liquid clouds, but also the total amount of ice cloud in the control climate must affect the size of the change in ice and liquid clouds caused by doubling $\mathrm{CO}_{2}$. 
Fig. 9 Zonal mean annually averaged cloud albedo forcing over $60 \mathrm{~S}$ to $30 \mathrm{~S}$ in control (black line) and $2 \times \mathrm{CO}_{2}$ (red line) climate experiments
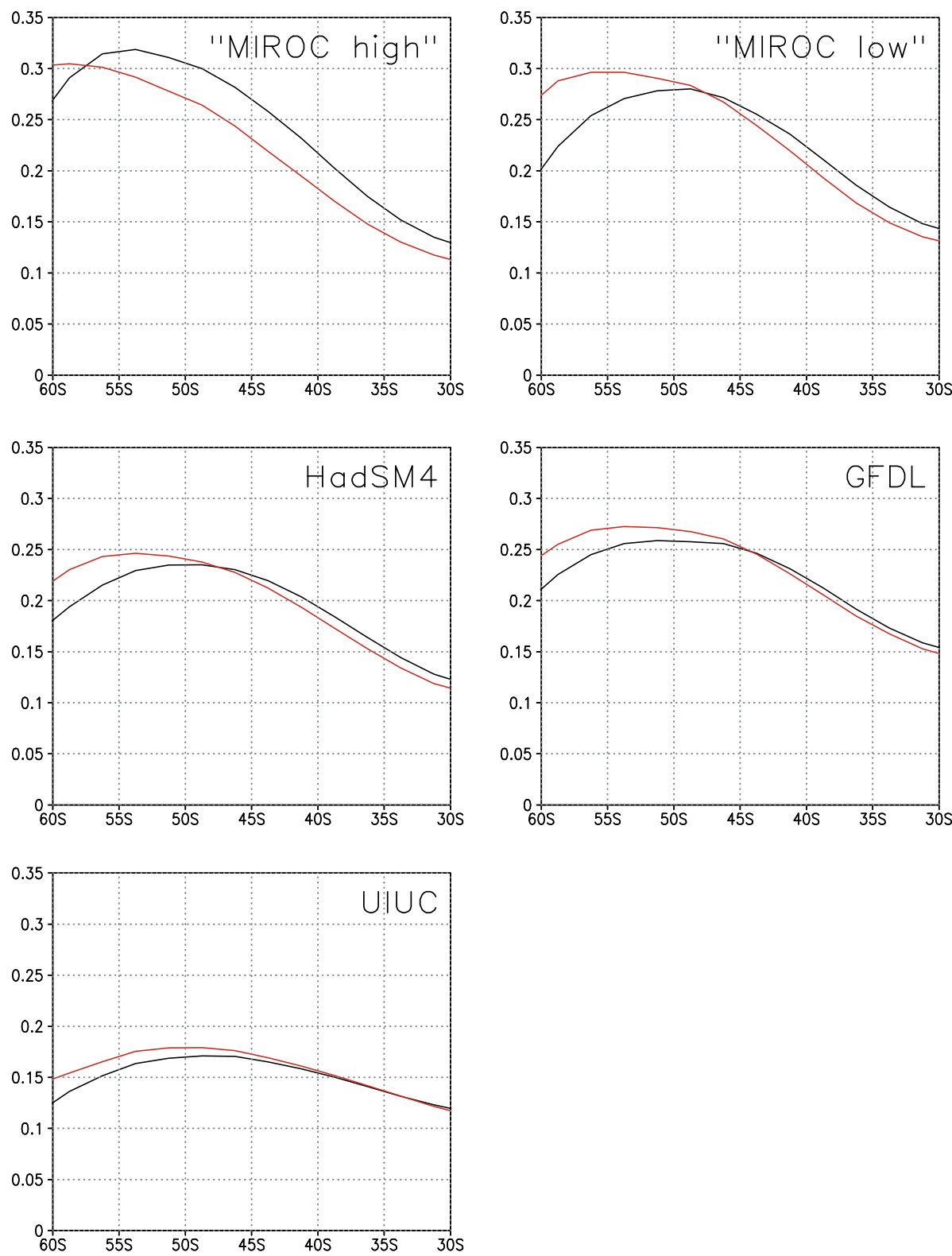

The reasons for the differences in the amount of ice cloud in the other 3 models are not so obvious, so we have performed further investigations. Figure 11 shows the zonal averaged relative humidity, cloud water of all phases, and ice cloud water from large-scale condensation averaged over the mixed phase band from -30 to $0^{\circ} \mathrm{C}$ in southern ocean region for the control climates of the 5 GCMs. The magnitude of the zonally averaged cloud water in the mixed phase layers of the 5 models are ranked in the same order as the magnitude of zonal averaged relative humidity in the layer. More cloud water stays in the layer in models with higher relative humidity. The magnitudes of the amounts of cloud ice in the different models are not, however, in the same order. This figure indicates that the parameterization of microphysical processes in each model as well as the relative humidity determines the amount of ice cloud.

Figure 12 shows the ratio of ice cloud to cloud water of all phases ( $x$-axis) in the vertical (temperature) level $(y$-axis) averaged over the southern ocean region in the control climates of the 5 GCMs. The ratio of cloud ice increases at lower temperatures in all models, but the
Table 3 Center of gravity of cloud water in control and $2 \times \mathrm{CO}_{2}$ climate. Climate sensitivity is shown for the reference

\begin{tabular}{lccccc}
\hline & UIUC & GFDL & HadSM4 & "MIROC low" & "MIROC high" \\
\hline Latitude $\left({ }^{\circ} \mathrm{S}\right)$ & 45.75 & 45.54 & 47.83 & 45.97 & 48.86 \\
Polar shift $\left({ }^{\circ}\right)$ & 0.94 & 1.09 & 1.17 & 1.60 & 3.45 \\
Climate sensitivity $\left({ }^{\circ} \mathrm{C}\right)$ & 2.3 & 2.9 & 3.6 & 4.0 & 6.3 \\
\hline
\end{tabular}




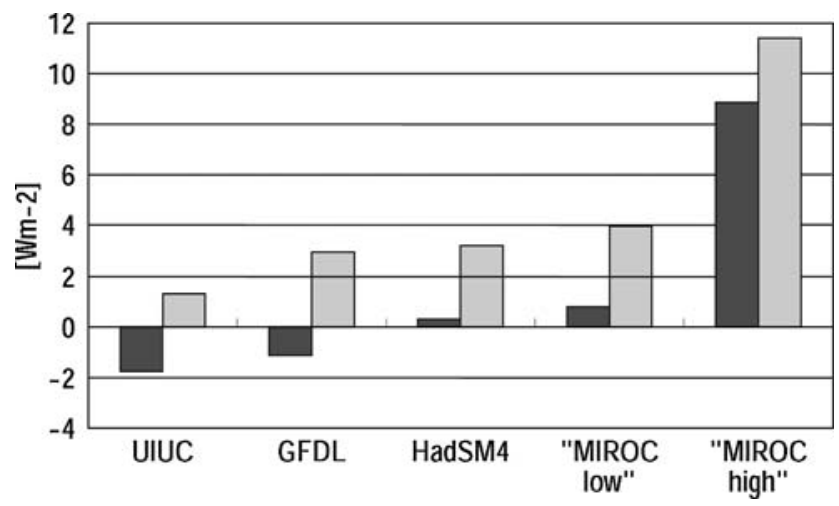

Fig. 10 The change in the annually averaged solar cloud forcings averaged over $60 \mathrm{~S}$ to $30 \mathrm{~S}$ for $2 \times \mathrm{CO}_{2}$ climate (black bars) and for the polar shift of cloud albedo forcing from $1 \times \mathrm{CO}_{2}$ climate (grey bars). Positive value indicates the decrease in reflection of solar radiation)

slope is quite different between models. Because the model output plotted here is a climatological average, it does not reproduce the exact ice/liquid rate dependency
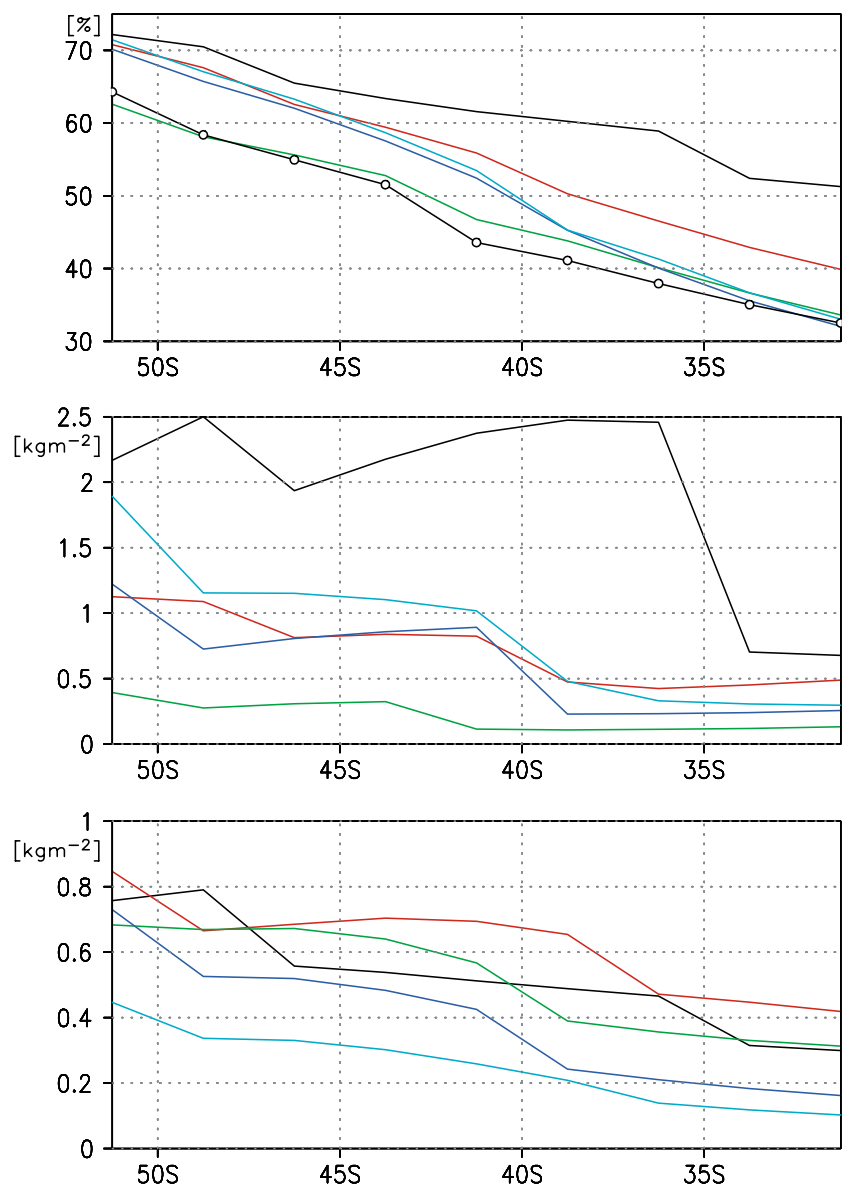

Fig. 11 Zonally averaged relative humidity [\%] (top), cloud water of all phase $\left[\mathrm{kg} / \mathrm{m}^{2}\right]$ (middle) and ice cloud water $\left[\mathrm{kg} / \mathrm{m}^{2}\right]$ (bottom) averaged over the mixed phase band from -30 to $0^{\circ} \mathrm{C}$ in southern ocean region in 5 GCMs (black: UIUC, red: GFDL, green: HadSM4, blue: "MIROC low", light blue: "MIROC high")

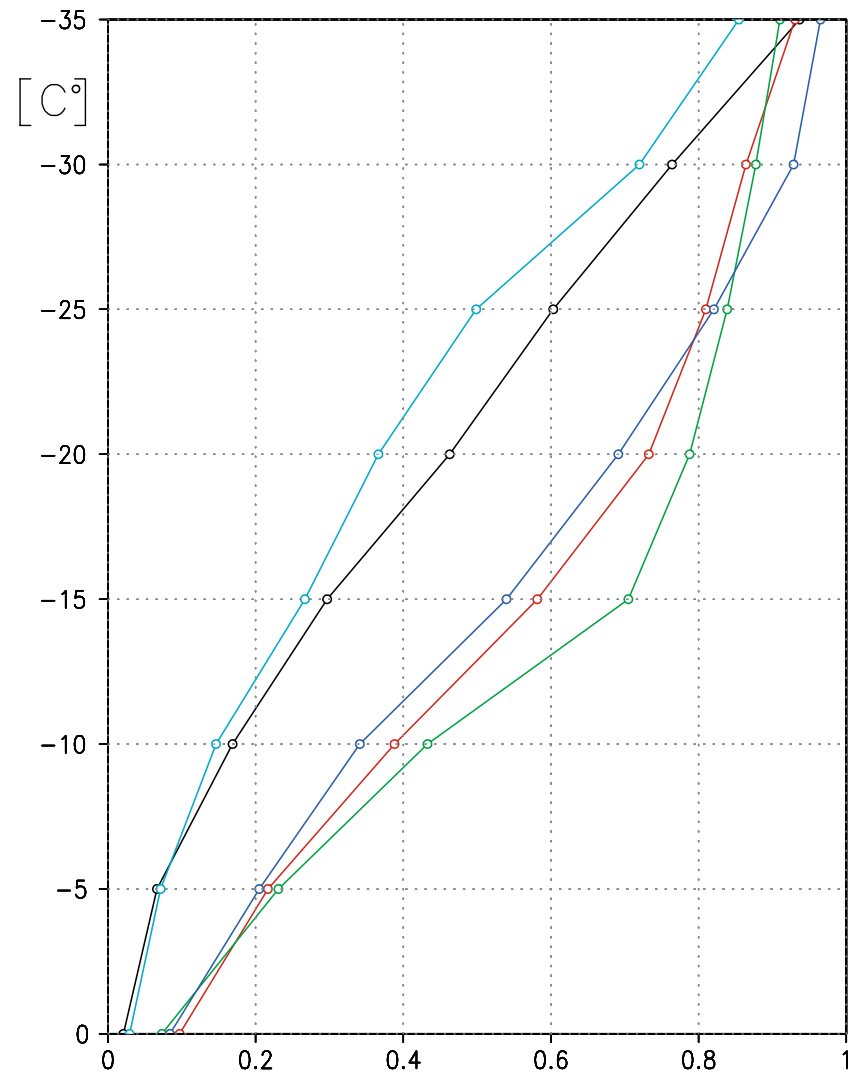

Fig. 12 Vertical (temperature) distribution of the ratio of ice cloud to cloud water of all phase averaged over $55 \mathrm{~S}$ to $30 \mathrm{~S} 5 \mathrm{GCMs}$ (black: UIUC, red: GFDL, green: HadSM4, blue: "MIROC low", light blue: "MIROC high")

on temperature in each model but we can see in this figure the difference in the cloud ice rate between the models. "MIROC low" has the higher threshold temperature of all cloud water defined to be ice in $-15^{\circ} \mathrm{C}$, whereas it is $-25^{\circ} \mathrm{C}$ in "MIROC high". In UIUC model, it is $-30^{\circ} \mathrm{C}$, and the slope is close to "MIROC high". In GFDL and HadSM4, most of cloud water is defined to be cloud ice when the temperature reaches $-15^{\circ} \mathrm{C}$. This is consistent with the modeled cloud ice/liquid rate relationship in these two models.

\section{Discussion}

This study shows initial results from the analysis of the cloud water distribution, and how it changes when the concentration of carbon dioxide is doubled, in 5 different GCMs. Although the distributions of cloud-water and the changes that occur under doubled carbon dioxide conditions vary between models, the analyses show that both the cloud-water profile in the control climate and its change for doubled carbon dioxide follow the threshold temperatures for the existence of liquid and ice cloud, which are modeled or defined in each cloud scheme. When carbon dioxide is doubled all models show changes in the mixed-phase layer cloud. 
The change in cloud water distribution that occurs under doubled carbon dioxide conditions is dominated by the distribution of cloud ice in the mixed-phase layer in the control climate. Cloud ice and cloud liquid decrease in the layer below the melting layer whereas an increase in cloud liquid occurs in the mixed-phase layer. Although the decrease in cloud liquid and cloud ice below the melting layer occurs at all latitudes, an increase in cloud liquid in the mixed-phase layer occurs only at latitudes where large amounts of cloud ice exist in the mixed phase layer. This change makes the distribution of cloud-water shift to higher latitudes where solar reflection decreases, because the solar insolation is smaller in higher latitude. The central latitude of the cloud water distribution shifts poleward, and the magnitude of this shift is larger for the higher climate sensitivity models.

We speculate that the models which have less cloud ice in the mixed-phase layer or those in which the concentration of cloud ice in the mixed-phase layer is restricted at high latitudes might have the poleward shift of cloud, leading to a positive solar cloud feedback and so resulting in higher climate sensitivity.

The fact that the ratio of cloud ice to total cloudwater follows the modeled cloud ice/liquid rate relationship shows that cloud ice distributions in mixedphase layers is strongly related to both the mixed-phase threshold temperatures and the total cloud water distributions. Our analyses suggest that the difference in the cloud water distributions in mixed-phase layers between models is closely related to the difference in relative humidity in the models. This might be because the dependency of cloud water on relative humidity is quite similar in both diagnostic and prognostic schemes, but the suggestion is that reproducing the observational atmospheric profile/distribution in the mixed-phase layer is especially important.

The threshold temperature for cloud liquid is around -10 to $-15^{\circ} \mathrm{C}$ in the models with prognostic cloud ice schemes. Although this is consistent to the observational study by Bower et al. (1996), it is still uncertain. The variation with temperature of the liquid fraction can be different between the shallower non-frontal stratiform clouds and deep frontal clouds as was noted by Ryan (1996) in a review of observations of precipitating layer clouds. Introducing physical properties related to mixed phase processes to convective schemes as well as largescale schemes may be a way to generate super-cooled liquid water at lower temperatures in frontal cloud systems. Observational data of the vertical profile of ice cloud, especially of the mixed phase is required for the understanding of cloud ice physical processes and improvement of the expression of these in climate models. Comparative analysis of the atmospheric profile in global cloud resolving model simulations (Tomita et al. 2004) will give us further understanding of the relationship between humidity and cloud water.

The statistical significance of these results has not been investigated due to the small sample size. The results can however form the basis for investigation in future work with more analyses, e.g., with the full CFMIP ensemble when it is available.

\section{References}

Andronova NG, Rozanov EV, Yang F, Schlesinger ME, Stenchikov GL (1999) Radiative forcing by volcanic aerosols from 1850 through 1994. J Geophys Res 104:807-816

Boucher O, Lohmann U (1995) The sulfate-CCN-cloud albedo effect. A sensitivity study with two general circulation models. Tellus 47B:281-300

Bower KN, Moss SJ, Johnson DW, Choularton TW, Latham J, Brown PRA, Blyth AM, Cardwell J (1996) A parameterization of the ice water content observed in frontal and convective clouds. Q J R Meteorol Soc 122:1815-1844

Cess RD, Potter GL, Blanchet JP, Boer GJ, Del Genio AD, Deque M, Dymnikov V, Galin V, Gates WL, Ghan SJ, Kiehl JT, Lacis AA, Le Treut H, Li Z-X, Liang X-Z, McAvaney BJ, Meleshko VP, Mitchell JFB, Morcrette J-J, Randall DA, Rikus L, Roeckner E, Royer JF, Schlese U, Sheinin DA, Slingo A, Sokolov AP, Taylor KE, Washington WM, Wetherald RT, Yagai I, Zhang M-H (1990) Intercomparison and interpretation of climate feedback processes in 19 atmospheric general circulation models. J Geophys Res 95:16601-16615

Charlock TP, Ramanathan V (1985) The albedo and cloud radiative forcing produced by a general circulation model with internally generated cloud optics. J Atmos Sci 42:1408-1429

Cober SG, Isaac George A, Korolev AV, Strapp JW (2001) Assessing cloud-phase conditions. J Appl Met 40(11):19671983

Donner LJ, Seman CJ, Soden BJ, Hemler RS, Warren JC, Strom J, Liou K-N (1997) Largescale ice clouds in the GFDL SKYHI general circulation model. J Geophys Res 102:21745-21768

Feigelson EM (1978) Preliminary radiation model of a cloudy atmosphere, 1, structure of clouds and solar radiation. Beitr Phys Atmos 51:203-229

Fowler D, Randall DA, Rutledge A (1996) Liquid and ice cloud microphysics in the CSU general circulation model. Part I: model description and simulated microphysical processes. J Clim 9:489-259

GFDL Global Atmospheric Model Development Team (2004) The new GFDL global atmosphere and land model AM2-LM2: evaluation with prescribed SST simulations. J Climate 17(24):4641-4673

Harrison EF, Minnis P, Barkstrom BR, Ramanathan V, Cess RD, Gibson GG (1990) Seasonal variation of cloud radiative forcing derived from the Earth Radiation Budget Experiment. J Geophys Res 95:18687-18703

Kållberg P, Simmons A, Uppala S, Fuentes M (2004) The ERA-40 archive, ERA-40 Project Report Series, No. 17, ECMWF. Available from http://www.ecmwf.int/publications/library/ecpublications/_pdf/era40/ERA40_PRS17.pdf

Kristjánsson $\mathrm{JE}^{-}$(1994) Tests of $\overline{\mathrm{a}}$ new cloud treatment in an atmospheric general circulation model. Physica D 77(1-3):2332

K-1 model developers (2004) K-1 coupled model (MIROC) description K-1 technical report, 1, H Hasumi and S Emori (eds) Center for Climate System Research, University of Tokyo, Available from http://www.ccsr.u-tokyo.ac.jp/kyosei/hasumi/ MIROC/tech-repo.pdf

Le Treut H, Li ZX (1991) Sensitivity of an atmospheric general circulation model to prescribed SST changes: feedback effects associated with the simulation of cloud optical properties. Clim Dyn 5:175-187

Lohmann U, Roeckner E (1996) Design and performance of a new cloud microphysics scheme developed for the ECHAM general circulation model. Clim Dyn 12:557-572

Martin GM, Johnson DW, Spice A (1994) The measurement and parameterization of effective radius of droplets in warm stratocumulus clouds. J Atmos Sci 51(13):1823-1842 
McAvaney BJ, Le Treut H (2003) The cloud feedback intercomparison project:(CFMIP). In CLIVAR Exchanges-supplementary contributions, 26 March 2003

Mitchell J, Ingram WJ (1992) $\mathrm{CO}_{2}$ and climate: a missing feedback? Nature 341:132-134

Nemesure S, Cess RD, Dutton EG, Deluisi JJ, Li Z, Leighton HG (1994) Impact of cloud on the shortwave radiation budget of the surface-atmosphere system for snow-covered surfaces. J Clim 4:579-585

Pope VD, Gallani ML, Rowntree PR, Stratton RA (2000) The impact of new physical parametrizations in the Hadley Centre climate model-HadAM3. Clim Dyn 16:123-146

Rotstayn LD (1997) A physically based scheme for the treatment of stratiform clouds and precipitation in large-scale models. I: description and evaluation of microphysical processes. Q J R Meteorol Soc 123:1227-1282

Rotstayn LD, Ryan BF, Katzfey J (2000) A scheme for calculation of the liquid fraction in mixed-phase clouds in large-scale models. Mon Wea Rev 128:1070-1088

Ryan BF (1996) On the global variation of precipitating layer clouds. Bull Am Meteor Soc 77:53-70

Senior CA, Mitchell JFB (1993) Carbon dioxide and climate: the impact of cloud parameterization. J Clim 6:393-418

Smith RNB (1990) A scheme for predicting layer clouds and their water content in a general circulation model. Q J R Meteorol Soc 116:435-460

Sundqvist H (1978) A parameterization scheme for non-convective condensation including prediction of cloud water content. Q J R Meteorol Soc 104:677-690

Sundqvist H (1988) Parametrization of condensation and associated clouds in models for weather prediction and general simulation. In: Schlesinger ME (ed) Physically based Modelling and simulation of climate and climatic change, Part I. Kluwer, Dordrecht, pp 433-461
Tiedtke M (1993) Representation of clouds in large-scale models. Mon Wea Rev 121:3040-3061

Tomita H, Miura H, Iga S, Nasuno T, Satoh M (2004) A global cloud-resolving simulation: preliminary results from an aqua planet experiment. Geophys Res Lett 32(8):L08805 10.1029/ 2005GL022459

Webb M, Senior C, Bony S, Morcrette JJ (2001) Combining ERBE and ISCCP data to assess clouds in the Hadley Centre, ECMWF and LMD atmospheric climate models. Clim Dyn 17:905-922

Webb MJ, Senior CA, Sexton DMH, Ingram WJ, Williams KD, Ringer MA, McAvaney BJ, Colman R, Soden BJ, Gudgel R, Knutson T, Emori S, Ogura T, Tsushima Y, Andronova N, Li B, Musat I, Bony S, Taylor K (2006) On the contribution of local feedback mechanisms to the range of climate sensitivity in two GCM ensembles. Clim Dyn. DOI 10.1007/s00382-0060111-2

Wetherald RT, Manabe S (1998) Cloud feedback process in a general circulation model. J Atmos Sci 45:1397-1415

Wilson RD, Ballard SP (1999) A Microphysically based precipitation scheme for the UK Meteorological Office Unified Model. Q J R Meteorol Soc 125:1607-1636

Yang F, Schlesinger ME, Rozanov EV (2000) Description and performance of the UIUC 24-layer stratosphere-troposphere general-circulation model. J Geophys Res 105(D14):1792517954

Yin J H (2005) A consistent poleward shift of the storm tracks in simulations of 21 st Century climate. Geophys Res Lett 32:L18701, DOI 10.1029/2005GL023684 